\title{
Individualized flow-controlled ventilation compared to best clinical practice pressure- controlled ventilation: a prospective randomized porcine study
}

Patrick Spraider ${ }^{1}$, Judith Martini ${ }^{1 *}$ (D) Julia Abram¹, Gabriel Putzer ${ }^{1}$, Bernhard Glodny ${ }^{2}$, Tobias Hell ${ }^{3}$, Tom Barnes ${ }^{4}$ and Dietmar Enk ${ }^{5}$

\begin{abstract}
Background: Flow-controlled ventilation is a novel ventilation method which allows to individualize ventilation according to dynamic lung mechanic limits based on direct tracheal pressure measurement at a stable constant gas flow during inspiration and expiration. The aim of this porcine study was to compare individualized flowcontrolled ventilation (FCV) and current guideline-conform pressure-controlled ventilation (PCV) in long-term ventilation.
\end{abstract}

Methods: Anesthetized pigs were ventilated with either FCV or PCV over a period of $10 \mathrm{~h}$ with a fixed $\mathrm{FiO}_{2}$ of 0.3 . FCV settings were individualized by compliance-guided positive end-expiratory pressure (PEEP) and peak pressure $\left(P_{\text {peak }}\right)$ titration. Flow was adjusted to maintain normocapnia and the inspiration to expiration ratio (l:E ratio) was set at 1:1. PCV was performed with a PEEP of $5 \mathrm{~cm} \mathrm{H}_{2} \mathrm{O}$ and $P_{\text {peak }}$ was set to achieve a tidal volume $\left(V_{T}\right)$ of $7 \mathrm{ml} / \mathrm{kg}$. The respiratory rate was adjusted to maintain normocapnia and the l:E ratio was set at 1:1.5. Repeated measurements during observation period were assessed by linear mixed-effects model.

Results: In FCV $(n=6)$, respiratory minute volume was significantly reduced (6.0 vs $12.7, \mathrm{MD}-6.8(-8.2$ to -5.4$) \mathrm{I} /$ min; $p<0.001)$ as compared to PCV $(n=6)$. Oxygenation was improved in the FCV group $\left(\mathrm{paO}_{2} 119.8\right.$ vs $96.6, \mathrm{MD}$ 23.2 (9.0 to 37.5) Torr; 15.97 vs $12.87, \mathrm{MD} 3.10$ (1.19 to 5.00) $\mathrm{kPa} ; p=0.010$ ) and $\mathrm{CO}_{2}$ removal was more efficient $\left(\mathrm{paCO}_{2} 40.1\right.$ vs $44.9, \mathrm{MD}-4.7$ ( -7.4 to -2.0$)$ Torr; 5.35 vs 5.98, MD $-0.63(-0.99$ to -0.27$\left.) \mathrm{kPa} ; p=0.006\right)$. $P_{\text {peak }}$ and driving pressure were comparable in both groups, whereas PEEP was significantly lower in FCV $(p=0.002)$. Computed tomography revealed a significant reduction in non-aerated lung tissue in individualized FCV ( $p=0.026)$ and no significant difference in overdistended lung tissue, although a significantly higher $V_{T}$ was applied (8.2 vs 7.6, MD 0.7 (0.2 to 1.2$) \mathrm{ml} / \mathrm{kg} ; p=0.025)$.

(Continued on next page)

\footnotetext{
* Correspondence: judith.martini@i-med.ac.at

${ }^{1}$ Department of Anaesthesia and Intensive Care Medicine, Medical University of Innsbruck, Innsbruck, Austria

Full list of author information is available at the end of the article
}

(c) The Author(s). 2020 Open Access This article is licensed under a Creative Commons Attribution 4.0 International License, which permits use, sharing, adaptation, distribution and reproduction in any medium or format, as long as you give appropriate credit to the original author(s) and the source, provide a link to the Creative Commons licence, and indicate if changes were made. The images or other third party material in this article are included in the article's Creative Commons licence, unless indicated otherwise in a credit line to the material. If material is not included in the article's Creative Commons licence and your intended use is not permitted by statutory regulation or exceeds the permitted use, you will need to obtain permission directly from the copyright holder. To view a copy of this licence, visit http://creativecommons.org/licenses/by/4.0/ The Creative Commons Public Domain Dedication waiver (http://creativecommons.org/publicdomain/zero/1.0/) applies to the data made available in this article, unless otherwise stated in a credit line to the data. 
(Continued from previous page)

Conclusion: Our long-term ventilation study demonstrates the applicability of a compliance-guided

individualization of FCV settings, which resulted in significantly improved gas exchange and lung tissue aeration without signs of overinflation as compared to best clinical practice PCV.

Keywords: Respiration, artificial, Ventilator-induced lung injury, Tomography, X-ray computed, Pulmonary atelectasis, Stress mechanical, Respiratory mechanics

\section{Background}

Ventilator-induced lung injury (VILI) is a serious complication in mechanically ventilated patients, significantly contributing to patient morbidity and mortality $[1,2]$. Despite numerous efforts during the last decade to optimize standard ventilation methods in order to minimize the probability of VILI, e.g., by decreasing tidal volume $\left(V_{\mathrm{T}}\right)$ and adjusting positive end-expiratory pressure (PEEP), the incidence of VILI is still high leading to pulmonary complications postoperatively as well as in ICU patients [1-3]. One inherent problem of artificial ventilation is the difficulty entailed in comprehensively determining individual lung mechanics from ventilation parameters and displayed measurements. In addition, setting the ventilator based on (predicted) body weight does not adequately address variations in lung mechanics [4].

Flow-controlled ventilation (FCV) is a ventilation mode in which flow is kept constant during both inspiration and expiration [5, 6]. This is a novelty in artificial ventilation. The resulting constant flow coupled with direct intratracheal pressure measurements allows much more precise analysis of individual lung mechanics than is possible in conventional ventilation modes, where flow varies over a wide range and intratracheal pressure is not directly accessible. In particular, FCV allows accurate determination of dynamic compliance and-based on this-precise adjustment of PEEP and peak pressure $\left(P_{\text {peak }}\right)$, thereby ensuring that ventilation occurs in the range between the (so-called) lower and upper inflection points of each patient's pressure-volume curve.

In addition, it has been shown that the energy applied to the lung tissue is a significant factor contributing to the development of VILI [7]. Energy dissipation in lung tissue is related to flow. Therefore, ventilation at constant flow (which avoids the high flow peaks as in conventional ventilation) leads to minimization of applied and-more importantly-dissipated energy [5]. There is growing awareness that energy dissipation during the ventilation cycle is related to VILI and thus its reduction seems to be a key factor in developing more protective ventilation strategies [6].

The aim of this study was to evaluate the applicability of individualized FCV and to examine-for the first time-the effects of individualized FCV on respiratory and metabolic parameters as well as on lung aeration in comparison to evidence-based, best clinical practice pressure-controlled ventilation (PCV) during long-term ventilation in pigs.

\section{Methods}

\section{Animal preparation}

Experiments were performed in 12 domestic pigs weighing 35 to $45 \mathrm{~kg}$. Animals were fasted overnight with free access to water. Intramuscular premedication was performed with azaperone $(4 \mathrm{mg} / \mathrm{kg})$ and atropine $(0.5 \mathrm{mg})$ before transportation to the experiment facility.

Sedation was deepened with an intramuscular injection of ketamine $(30 \mathrm{mg} / \mathrm{kg})$. After being placed in supine position animals were intubated with an $8.0-\mathrm{mm}$ internal diameter endotracheal tube (ETT) (Willy Rüsch $\mathrm{GmbH}$, Kernen, Germany) followed by injection of propofol $(2 \mathrm{mg} / \mathrm{kg})$ and rocuronium $(1 \mathrm{mg} / \mathrm{kg})$ via an ear vein cannula. Anesthesia was maintained with a continuous infusion of propofol (6 to $8 \mathrm{mg} / \mathrm{kg} / \mathrm{h}$ ), remifentanil $(0.2$ to $0.3 \mu \mathrm{g} / \mathrm{kg} / \mathrm{h})$, and rocuronium $(0.5 \mathrm{mg} / \mathrm{kg} / \mathrm{h})$. Following induction, baseline ventilation using volumecontrolled ventilation (VCV) was initiated (Julian; Dräger Medical, Lübeck, Germany) with an $\mathrm{FiO}_{2}$ of 0.3 and a $V_{\mathrm{T}}$ of $7 \mathrm{ml} / \mathrm{kg}$ body weight, a PEEP of $5 \mathrm{~cm} \mathrm{H}_{2} \mathrm{O}$ and an inspiration-to-expiration ratio (I:E ratio) of 1:1.5. Respiratory rate (RR) was adjusted to maintain normocapnia ( $\mathrm{paCO}_{2} 35$ to 45 Torr; 4.7 to $6.0 \mathrm{kPa}$ ). Normovolemia was maintained by infusion of a balanced crystalloid solution (5 to $10 \mathrm{ml} / \mathrm{kg} / \mathrm{h}$ Elomel iso; Fresenius Kabi Austria GmbH, Graz, Austria).

This anesthetic regime has been proven to guarantee appropriate depth of anesthesia without hemodynamic disturbances [8].

Before starting invasive instrumentation $1.5 \mathrm{~g}$ cefuroxime was administered intravenously and repeated after 4 $\mathrm{h}$ to prevent septic complications. For invasive arterial pressure monitoring and arterial blood gas sampling an introducer sheath (5 F; Arrow, Reading, PA, USA) was advanced under ultrasound guidance via the femoral artery. A pulmonary artery catheter (7 F; Edwards Life Science, Irvine, CA, USA) was positioned via the right internal jugular vein after ultrasound-guided introducer sheath insertion (8.5 F; Arrow, Reading, PA, USA). A pig-tail catheter (8 F; Bard, Tempe, AZ, USA) was inserted into the bladder after ultrasound-guided 
puncture of the bladder for urine release and an esophageal probe (14 F; NutriVent, Sidam S.R.L., Mirandola, MO, Italy) positioned for monitoring of esophageal pressure $\left(P_{\mathrm{es}}\right)$ as a surrogate parameter for pleural pressure.

\section{Experiment protocol}

After instrumentation, the animal was allowed to stabilize for $15 \mathrm{~min}$ before baseline measurements were obtained and the protocol was started with pre-oxygenation followed by an apnea phase, where the tracheal tube was disconnected from the ventilator for $1 \mathrm{~min}$.

Animals were randomized to FCV or PCV. In FCV animals the apnea phase was used to insert a $2.3-\mathrm{mm}$ internal diameter endotracheal tube (Tritube ${ }^{\circ}$; Ventinova Medical B.V., Eindhoven, The Netherlands) into the standard ETT. Subsequently, ventilation was started with either FCV (Evone'; Ventinova Medical B.V., Eindhoven, The Netherlands) or PCV (Evita $\mathrm{XL}^{\circ}$; Dräger, Lübeck, Germany) with a fixed $\mathrm{FiO}_{2}$ of 0.3. PCV was performed with a PEEP of $5 \mathrm{~cm} \mathrm{H}_{2} \mathrm{O}, P_{\text {peak }}$ set to achieve a $V_{\mathrm{T}}$ of 7 $\mathrm{ml} / \mathrm{kg}$ and the $\mathrm{RR}$ adjusted to maintain normocapnia $\left(\mathrm{paCO}_{2} 35\right.$ to 45 Torr; 4.7 to $\left.6.0 \mathrm{kPa}\right)$. The I:E ratio was maintained at 1:1.5. FCV was performed with compliance-guided PEEP and $P_{\text {peak }}$ settings (see below), and the flow was adjusted to maintain normocapnia. The I:E ratio was set at 1:1.

Measurement points were defined as T0 before commencement of the intervention period (baseline) with T1 to T14 at $0,15,30,45,60,120,180,240,300,360,420$, 480, 540, and $600 \mathrm{~min}$ after initiating either FCV or PCV. Mechanical ventilation was performed for $10 \mathrm{~h}$ in supine position without any recruitment maneuvers. The study ended with a CT scan of the chest immediately after the intervention period.

\section{Individualization of flow-controlled ventilation (FCV)}

If the animal was randomized to FCV, ventilation was performed with the Evone ${ }^{\bullet}$ ventilator (Ventinova
Medical B.V., Eindhoven, the Netherlands). Individualization of FCV by compliance-guided titration of PEEP and $P_{\text {peak }}$ was performed as follows: first, the PEEP was stepwise increased or decreased while maintaining the same driving pressure until the highest $V_{\mathrm{T}}$ was reached. Subsequently, $P_{\text {peak }}$ was increased stepwise as long as the $V_{\mathrm{T}}$ showed an-based on measured dynamic compliance-at least slightly overproportional rise (Fig. 1). Finally, the flow was set to maintain normocapnia at an I:E ratio of 1:1, which is best for minimizing dissipated energy $[5,6]$. Thus, half of the flow roughly represented the respiratory minute volume (MV) for FCV.

\section{Respiratory and cardiovascular measurements}

Respiratory and cardiovascular measurements were taken at T0 to T14 (defined above). MV, $V_{\mathrm{T}}$, and RR were recorded directly from the ventilator. Measured $P_{\text {peak }}$ was documented as displayed for FCV as well as PCV, where an observed zero flow phase at $P_{\text {peak }}$ indicated equilibrium between airway pressure and tracheal pressure. PEEP was additionally checked for intrinsic increments to rule out air trapping in PCV.

Arterial blood gas samples were obtained and $\mathrm{paO}_{2}$ and $\mathrm{paCO}_{2}$ measured (ABL800 Flex ${ }^{\circ}$; Radiometer, Brønshøj, Denmark).

Cardiovascular monitoring included heart rate (HR), mean arterial pressure (MAP), mean pulmonary arterial pressure (MPAP), and central venous pressure (CVP). Cardiac output (CO) and systemic and pulmonary vascular resistance (SVR, PVR) were measured by threefold injection of $10 \mathrm{ml}$ of saline via the pulmonary arterial catheter. CO, SVR, and PVR indices were calculated using the predicted body surface area for pigs [9].

\section{Computed tomography and image postprocessing}

To assess inspiratory and expiratory lung aeration two scans were performed with appropriate hold maneuvers lasting approximately $5 \mathrm{~s}$ to obtain images of the lung
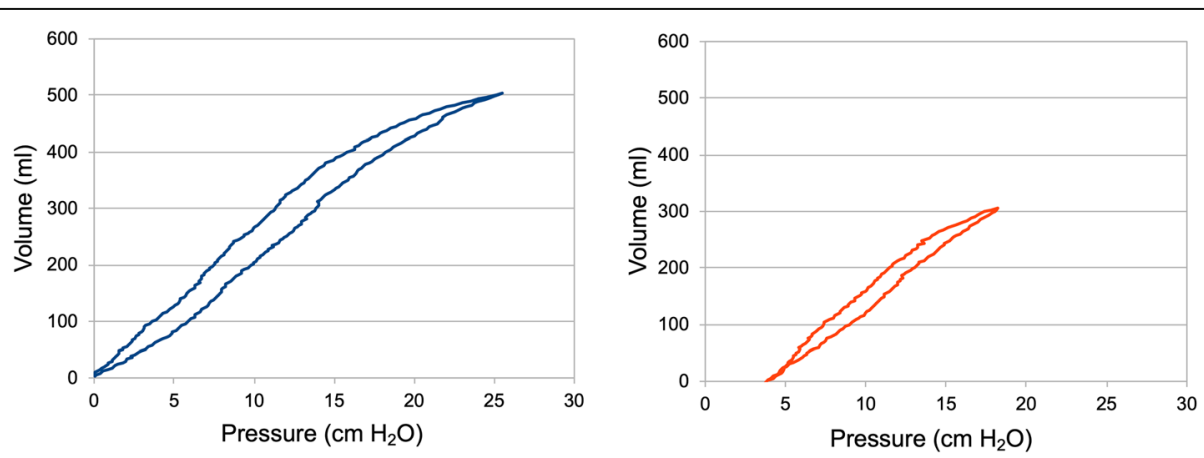

Fig. 1 The pressure-volume loop (PV loop) obtained from intratracheal pressure measurement in a pilot animal. In the left graph, ventilation was performed without positive end-expiratory pressure (PEEP) and a peak pressure $\left(P_{\text {peak }}\right)$ of $25 \mathrm{~cm} \mathrm{H}_{2} \mathrm{O}$, showing a sigmoid shape of the PV loop. After compliance-guided pressure adjustment PEEP was set to $4 \mathrm{~cm} \mathrm{H}_{2} \mathrm{O}$ and $P_{\text {peak }}$ to $18 \mathrm{~cm} \mathrm{H}_{2} \mathrm{O}$, resulting in an almost linear relation between pressure and volume (right graph) 
after $10 \mathrm{~h}$ of ventilation. The ventilation settings remained otherwise unchanged. All examinations were done with a Somatom Confidence ${ }^{\oplus}$ CT scanner (Siemens Healthineers, Erlangen, Germany). The settings were as follows: tube voltage $120 \mathrm{kV}$, tube current $600 \mathrm{~mA}$ (without exposure modulation), single collimation width 0.6 $\mathrm{mm}$, slice thickness $0.75 \mathrm{~mm}$, total collimation width $19.2 \mathrm{~mm}$, table speed $57.6 \mathrm{~mm}$, table feed per rotation $28.8 \mathrm{~mm}$, spiral pitch 1.5 , matrix $512 \times 512$, window center 50/-600, window width $350 / 1200 \mathrm{HU}$, convolution kernel I40f/3 and B70F, and a field of view $294 \mathrm{~mm}$. For image processing an AW Server Workstation (AWS Version 3.2, Volume Viewer program; General Electric, Boston, MA, USA) was used. The lungs were segmented semi-automatically. Then, the total lung volume was determined automatically, as well as the lung volumes at different Hounsfield unit (HU) thresholds in $50 \mathrm{HU}$ intervals. As described by Gattinoni et al. [10], nonaerated lung tissue was defined as absorption values between 100 and $-100 \mathrm{HU}$, poorly aerated lung tissue as values between -101 and $-500 \mathrm{HU}$, normally aerated lung tissue as values between -501 and $-900 \mathrm{HU}$, and airway as well as overdistended lung tissue as values between -901 and $-1000 \mathrm{HU}$.

\section{Statistical analysis}

A mathematician (TH) not involved in the study procedures performed the statistical analyses using $\mathrm{R}$, version 3.5.3. Continuous data were presented as median (25th to 75th percentile) and categorical variables as frequencies (\%). Effect size and precision were shown with estimated median differences between groups for continuous data and odds ratios (OR) for binary variables with $95 \%$ confidence intervals (CI). All statistical assessments were twosided, and a significance level of $5 \%$ was used. The Wilcoxon rank sum test and Fisher's exact test were applied to assess differences between the groups.

The progression of measurements from T0 to T14 was illustrated per group using the median course with corresponding 95\% CI's. Differences between groups were assessed with linear mixed-effects models with random intercepts for time points and subjects as well as group as fixed effects.

Differences in the Hounsfield unit (HU) distribution in non-aerated and normally aerated regions were assessed by applying the Wilcoxon rank sum test to the area under the curve.

\section{Results}

The experiment protocol was completed in 12 pigs.

\section{Respiratory and cardiovascular measurements}

Baseline characteristics were comparable in both groups except for a significantly higher MV in PCV animals due to a slightly (non-significantly) higher body weight (Table 1).

During the observation period of $10 \mathrm{~h}, P_{\text {peak }}$ was comparable in both groups, whereas PEEP was significantly lower in FCV $(p=0.002$, Table 2$)$. $V_{\mathrm{T}}$ was significantly higher in FCV than in PCV (8.2 vs 7.6, MD 0.7 (0.2 to 1.2) $\mathrm{ml} / \mathrm{kg} ; p=0.025)$. RR in PCV was twice as high as in FCV (20.1 vs $41.5, \mathrm{MD}-21.3$ ( -22.8 to -19.9$) / \mathrm{min}$; $p<0.001)$. MV was significantly lower in the FCV group (6.0 vs $12.7, \mathrm{MD}-6.8(-8.2$ to -5.4$) 1 / \mathrm{min} ; p<0.001$, Fig. 2) than in the PCV group, as well as calculated mechanical power $(5.8$ vs $22.0, \mathrm{MD}-16.2(-21.1$ to - 11.4) $\mathrm{J} / \mathrm{min}$; $p<0.001$ ) [11]. FCV animals showed significantly improved oxygenation $\left(\mathrm{paO}_{2} 119.8\right.$ vs 96.6, MD 23.2 (9.0 to 37.5) Torr; 15.97 vs 12.87, MD 3.10 (1.19 to 5.00$) \mathrm{kPa} ; p=0.010$, Fig. 2) as well as $\mathrm{CO}_{2}$ removal $\left(\mathrm{paCO}_{2} 40.1\right.$ vs 44.9 , MD $-4.7(-7.4$ to -2.0$)$ Torr; 5.35 vs $5.98, \mathrm{MD}-0.63(-0.99$ to -0.27$) \mathrm{kPa} ;=$ 0.006, Fig. 2) as compared to PCV animals.

Vascular resistance indices PVRI (327.2 vs 260.2, MD $67.0(20.9$ to 113.1$)$ dyn $\left.\mathrm{s} / \mathrm{cm}^{5} / \mathrm{m}^{2} ; p=0.017\right)$ and SVRI (1646.1 vs 1353.0, MD 293.1 (51.4 to 534.7 ) dyn $\mathrm{s} / \mathrm{cm}^{5} /$ $\left.\mathrm{m}^{2} ; p=0.039\right)$ were significantly higher in the FCV group although no effects on other hemodynamic parameters (HR, MAP, MPAP, CVP, and CI) were observed (Table 2).

\section{Computed tomography}

Chest CT scans were obtained in inspiratory and expiratory hold. Classification of the lung tissue proportion at inspiration in overdistended (HU range of -1000 to -901), normally aerated (HU range of -900 to -501 ), poorly aerated (-500 to -101$)$ and non-aerated $(-100$ to 100) lung areas revealed a significant reduction in non-aerated lung tissue in FCV $(p=0.026$, Fig. 3$)$. Otherwise, there were no significant differences in overdistended, normally aerated and poorly aerated lung tissue in FCV as compared to PCV. Analysis of end-expiratory lung volume (EELV) revealed comparable results in both groups (FCV 545.9 vs PCV 604.6, MD - 19.6 (- 161.0 to 140.9) $\mathrm{ml} ; p=0.589$ ).

In order to visualize the differences in ventilation mode, a cinematic CT scan of an FCV and PCV representative was obtained, which is provided as digital content (Additional file 1). RR was reduced to 10 per minute, otherwise the settings of the ventilator remained unchanged. The video clearly reveals the smooth and steady changes in lung volume during inspiration and expiration without any interruptions during the ventilation cycle in FCV. In contrast, when administering PCV rapid changes in lung volume can be noted, which are caused by decelerating flow during inspiration and expiration, resulting in pause phases without tissue movement. 
Table 1 Characteristics of laboratory animals before the start of the experiment

\begin{tabular}{|c|c|c|c|c|c|c|}
\hline & & Total $(n=12)$ & FCV $(n=6)$ & PCV $(n=6)$ & MD with $95 \% \mathrm{Cl}^{\mathrm{a}}$ & $p$ value $^{b}$ \\
\hline \multicolumn{7}{|c|}{ Demographic data } \\
\hline Weight & $\mathrm{kg}$ & $37.8(33.8-43.3)$ & $36.2(32.9-38.7)$ & $40.5(36.6-44.8)$ & -4.1 ( -11.6 to 2.3$)$ & 0.240 \\
\hline Size & $\mathrm{m}$ & $1.08(1.07-1.10)$ & $1.08(1.06-1.10)$ & $1.08(1.07-1.14)$ & $-0.03(-0.09$ to 0.03$)$ & 0.511 \\
\hline Gender & female & 7/12 (58.3\%) & 4/6 (66.7\%) & $3 / 6(50 \%)$ & 0.53 (0.03 to 8.30) & 1 \\
\hline \multicolumn{7}{|c|}{ Monitoring data } \\
\hline$H R$ & $/ \mathrm{min}$ & $89.0(81.0-95.5)$ & $91.0(84.0-94.3)$ & $85.0(76.8-94.8)$ & $3.9(-8.0$ to 20.0$)$ & 0.521 \\
\hline MAP & $\mathrm{mm} \mathrm{Hg}$ & $65.5(63.0-72.0)$ & $73.0(66.5-75.75)$ & $63.0(63.0-65.3)$ & $8.0(-4.0$ to 15.0$)$ & 0.106 \\
\hline MPAP & $\mathrm{mm} \mathrm{Hg}$ & $22.0(20.0-23.3)$ & $21.0(20.3-24.8)$ & $23.0(20.8-23.0)$ & $-0.5(-4.0$ to 8.0$)$ & 1 \\
\hline CVP & $\mathrm{mm} \mathrm{Hg}$ & $10.0(8.0-13.0)$ & $9.0(8.0-10.0)$ & $13.0(10.8-13.0)$ & $-3.0(-6.0$ to 6.0$)$ & 0.220 \\
\hline $\mathrm{Cl}$ & $\mathrm{l} / \mathrm{min} / \mathrm{m}^{2}$ & $6.1(5.7-6.6)$ & $6.0(5.6-6.4)$ & $6.2(5.9-7.5)$ & $-0.4(-2.2$ to 0.7$)$ & 0.485 \\
\hline PCWP & $\mathrm{mmHg}$ & $11.0(9.0-13.0)$ & $10.0(6.0-11.0)$ & $12.5(11.3-13.0)$ & $-3.0(-8.0$ to 2.0$)$ & 0.195 \\
\hline$V_{T}$ & $\mathrm{ml} / \mathrm{kg}$ & $7.1(7.1-7.5)$ & $7.2(7.1-7.7)$ & $7.1(7.0-7.3)$ & $0.1(-0.3$ to 0.9$)$ & 0.191 \\
\hline RR & $/ \mathrm{min}$ & $35.0(33.8-37.3)$ & $34.0(31.0-36.3)$ & $36 . .0(34.5-37.5)$ & $-2.0(-8.0$ to 2.0$)$ & 0.332 \\
\hline MV & $1 / \min$ & $9.5(9.0-11.6)$ & $9.1(8.9-9.4)$ & $11.6(10.1-11.8)$ & $-2.4(-4.3$ to -0.1$)$ & $0.041^{*}$ \\
\hline$P_{\text {peak }}$ & $\mathrm{cm} \mathrm{H} \mathrm{H}_{2} \mathrm{O}$ & $19.5(18.0-22.5)$ & $18.5(18.0-19.8)$ & $23.0(19.0-27.0)$ & $-4.0(-10.0$ to 1.0$)$ & 0.195 \\
\hline$\Delta P$ & $\mathrm{~cm} \mathrm{H} \mathrm{H}_{2} \mathrm{O}$ & $14.5(13.0-17.5)$ & $13.5(13.0-14.8)$ & $18.0(14.0-22.0)$ & $-4.0(-10.0$ to 1.0$)$ & 0.195 \\
\hline$P_{\mathrm{es}}$ & $\mathrm{cm} \mathrm{H}{ }_{2} \mathrm{O}$ & $12.0(12.0-15.0)$ & $12.0(12.0-15.0)$ & $12.5(12.0-14.5)$ & $0.0(-4.0$ to 3.0$)$ & 0.924 \\
\hline \multirow[t]{2}{*}{$\mathrm{paCO}_{2}$} & Torr & $41.1(39.3-43.3)$ & $40.4(39.0-42.8)$ & $41.8(40.0-42.9)$ & $-0.9(-4.6$ to 2.5$)$ & 0.699 \\
\hline & $\mathrm{kPa}$ & $5.47(5.24-5.77)$ & $5.38(5.20-5.70)$ & $5.57(5.33-57.20)$ & $-0.12(-0.61$ to 0.33$)$ & \\
\hline \multirow[t]{2}{*}{$\mathrm{paO}_{2}$} & Torr & $120.5(97.8-127.3)$ & $113.5(99.8-123.5)$ & $123.0(95.8-130.8)$ & $-4.5(-30.0$ to 34.0$)$ & 0.818 \\
\hline & $\mathrm{kPa}$ & 16.07 (13.03-16.97) & $15.13(13.30-16.47)$ & $16.40(12.77-17.43)$ & $-0.60(-4.00$ to 4.53$)$ & \\
\hline
\end{tabular}

$\mathrm{Cl}$ cardiac index, CVP central venous pressure, FCV flow-controlled ventilation, $H R$ heart rate, MAP mean arterial pressure, MD mean difference, MPAP mean pulmonary arterial pressure, $M V$ respiratory minute volume, $\mathrm{paCO}_{2}$ arterial partial pressure of carbon dioxide, $p a \mathrm{O}_{2}$ arterial partial pressure of oxygen, $P C V$ pressure-controlled ventilation, $P C W P$ pulmonary capillary wedge pressure, $P_{e s}$ esophageal pressure, $P_{\text {peak }}$ peak pressure, $R R$ respiratory rate, $V_{T}$ tidal volume, $\triangle P$ driving pressure (difference between positive end-expiratory pressure and peak pressure);

Binary data are presented as no./total no. (\%), continuous data as medians (25th to 75 th percentile)

${ }^{a}$ Odds ratios for binary variables and estimated median difference for continuous variables

${ }^{b}$ Assessed by Fisher's exact test for categorical variables and Wilcoxon rank sum test for continuous variables

\section{Discussion}

The main finding of this study is the applicability of compliance-guided individualization of FCV settings. Tailored ventilator settings meet today's ambitions of precision medicine and individual patient needs much better than do fixed numbers or thresholds for every patient.. We showed that compliance-guided pressure adjustment with FCV did not cause more regional overinflation of lung tissue when compared to evidence-based, low tidal volume PCV even though higher $V_{\mathrm{T}} \mathrm{S}$ were applied with FCV. Several studies report a significant improvement in ventilation efficiency and aeration of lung tissue when FCV is applied [12-16]; however, these studies did not use an individualized ventilation approach. Our study shows that normocapnia was maintained in individualized FCV despite a remarkable reduction of respiratory minute volume by $50 \%$ compared to PCV. Second, individualized FCV resulted in significantly improved oxygenation and a significant reduction of non-aerated lung tissue indicating an improvement of ventilation efficiency and lung aeration.

Several factors contributing to improved ventilation efficiency were found for FCV. First, in animals ventilated with FCV dead space ventilation was significantly reduced by increasing $V_{\mathrm{T}}$. The finding of increased $V_{\mathrm{T}}$ may be counterintuitive in terms of lung-protective ventilation at first sight since studies have clearly shown that higher tidal volumes may be associated with a negative outcome in ARDS [17]. However, the primary idea of FCV is to physically reduce dissipated energy applied to lung tissue as much as possible. The only way to minimize dissipated energy is to keep gas flow constant during the entire ventilation cycle and at the lowest possible level $[5,6]$. With minimized gas flow, ventilation must be as efficient as possible; therefore, tidal volume was increased within lung mechanic limits to reduce dead space ventilation but simultaneously decrease the risk of atelectasis and/or overdistension (Fig. 1). This process is aided by the viscoelastic properties of the lung 
Table 2 Course of parameters over $10 \mathrm{~h}$ with estimated differences between groups

\begin{tabular}{|c|c|c|c|c|c|}
\hline & & FCV mean $^{a}$ & PCV mean $^{a}$ & MD with $95 \% \mathrm{Cl}^{\mathrm{a}}$ & $p$ value $^{a}$ \\
\hline$H R$ & $/ \min$ & 84.0 & 79.6 & $4.4(-5.0$ to 13.8$)$ & 0.378 \\
\hline MAP & $\mathrm{mmHg}$ & 70.1 & 65.1 & $5.0(-0.3$ to 10.4$)$ & 0.093 \\
\hline MPAP & $\mathrm{mmHg}$ & 21.8 & 22.8 & $-1.0(-4.8$ to 2.8$)$ & 0.615 \\
\hline CVP & $\mathrm{mmHg}$ & 9.5 & 12.1 & $-2.6(-6.1$ to 0.9$)$ & 0.177 \\
\hline $\mathrm{Cl}$ & $1 / \mathrm{min} / \mathrm{m}^{2}$ & 5.4 & 5.7 & $-0.3(-1.0$ to 0.4$)$ & 0.410 \\
\hline PCWP & $\mathrm{mmHg}$ & 9.5 & 12.6 & $-3.1(-6.5$ to 0.3$)$ & 0.108 \\
\hline PVRI & dyn $\mathrm{s} / \mathrm{cm}^{5} / \mathrm{m}^{2}$ & 327.2 & 260.2 & $67.0(20.9$ to 113.1$)$ & $0.017^{*}$ \\
\hline SVRI & dyn $\mathrm{s} / \mathrm{cm}^{5} / \mathrm{m}^{2}$ & 1646.1 & 1353.0 & 293.1 (51.4 to 534.7) & $0.039^{*}$ \\
\hline$P_{\text {es }}$ & $\mathrm{cm} \mathrm{H} \mathrm{H}_{2} \mathrm{O}$ & 12.3 & 13.9 & $-1.6(-3.7$ to 0.5$)$ & 0.178 \\
\hline$V_{T}$ & $\mathrm{ml} / \mathrm{kg}$ & 8.2 & 7.6 & 0.7 (0.2 to 1.2$)$ & $0.025^{*}$ \\
\hline $\mathrm{RR}$ & $/ \min$ & 20.1 & 41.5 & $-21.3(-22.8$ to -19.9$)$ & $<0.001^{* * *}$ \\
\hline$P_{\text {peak }}$ & $\mathrm{cm} \mathrm{H}_{2} \mathrm{O}$ & 16.3 & 17.5 & $-1.2(-3.5$ to 1.2$)$ & 0.350 \\
\hline$\Delta \mathrm{P}$ & $\mathrm{cm} \mathrm{H}_{2} \mathrm{O}$ & 13.0 & 12.5 & $0.6(-1.7$ to 2.8$)$ & 0.638 \\
\hline MP & $\mathrm{J} / \mathrm{min}$ & 5.8 & 22.0 & $-16.2(-21.1$ to -11.4$)$ & $<0.001^{* * *}$ \\
\hline MV & $1 / \min$ & 6.0 & 12.7 & $-6.8(-8.2$ to -5.4$)$ & $<0.001^{* * *}$ \\
\hline \multirow[t]{2}{*}{$\mathrm{paCO}_{2}$} & Torr & 40.1 & 44.9 & $-4.7(-7.4$ to -2.0$)$ & \multirow[t]{2}{*}{$0.006^{* *}$} \\
\hline & $\mathrm{kPa}$ & 5.35 & 5.98 & $-0.63(-0.99$ to -0.27$)$ & \\
\hline \multirow[t]{2}{*}{$\mathrm{paO}_{2}$} & Torr & 119.8 & 96.6 & 23.2 (9.0 to 37.5 ) & \multirow[t]{2}{*}{$0.010^{*}$} \\
\hline & $\mathrm{kPa}$ & 15.97 & 12.87 & $3.10(1.19$ to 5.00$)$ & \\
\hline PEEP & & $\mathrm{FCV}^{\mathrm{b}}$ & $\mathrm{PCV}^{\mathrm{b}}$ & & $p$ value $^{c}$ \\
\hline 5 & $\mathrm{~cm} \mathrm{H} \mathrm{H}_{2} \mathrm{O}$ & $1 / 6(17 \%)$ & $6 / 6(100 \%)$ & & $0.002^{* *}$ \\
\hline 4 & $\mathrm{~cm} \mathrm{H} \mathrm{H}_{2} \mathrm{O}$ & $0 / 6(0 \%)$ & 0/6 (0\%) & & - \\
\hline 3 & $\mathrm{~cm} \mathrm{H} \mathrm{H}_{2} \mathrm{O}$ & 5/6 (83\%) & 0/6 (0\%) & & - \\
\hline
\end{tabular}

$\mathrm{Cl}$ cardiac index, CVP central venous pressure, $F C V$ flow-controlled ventilation, $H R$ heart rate, MAP mean arterial pressure, $M D$ mean difference, $M P$ mechanical power, MPAP mean pulmonary arterial pressure, $M V$ respiratory minute volume, $\mathrm{paCO}_{2}$ arterial partial pressure of carbon dioxide, $p a \mathrm{O}_{2}$ arterial partial pressure of oxygen, $P C V$ pressure-controlled ventilation, $P C W P$ pulmonary capillary wedge pressure, $P E E P$ positive end-expiratory pressure, $P_{e s}$ esophageal pressure, $P_{\text {peak }}$ peak pressure, $P V R I$ pulmonary vascular resistance index, $R R$ respiratory rate, $S V R I$ systemic vascular resistance index, $V_{T}$ tidal volume, $\triangle P$ driving pressure (difference between positive end-expiratory pressure and peak pressure)

${ }^{a}$ Estimated mean and median difference with $\mathrm{Cl}$ for continuous variables retrieved from linear mixed-effects model

${ }^{b}$ Binary data are presented as no./total no. (\%)

${ }^{c}$ Assessed by Fisher's exact test

tissue-it has more time to "creep" and relieve stress in FCV. In fact, the combination of direct intratracheal pressure measurement and a constant flow allows for the first time to measure dynamic compliance during ventilation and pressure settings were adjusted accordingly. The novelty in individualized FCV is that tidal volume is naturally strongly related to individual lung compliance as a result of the individualization process, thereby representing the ventilation of the available aerated lung tissue. This can lead to a higher $V_{\mathrm{T}}$ in lung healthy individuals (as shown in this study) but would also result in decreased $V_{\mathrm{T}}$ if the compliance of an injured lung is reduced.

In addition, improved lung aeration with less atelectasis was observed in FCV animals, even though a lower PEEP level was established than with PCV. These findings agree with those of previous studies, where a recruiting effect due to a linearized expiratory airway pressure decline was supposed for FCV [12, 13]. In fact, controlling expiratory flow mimics physiological effects provided by the glottis (acting as a dynamic resistor to the egress of gas) and the diaphragm (slowing down expiratory flow by controlled muscle relaxation). As already mentioned above, the observed higher $V_{\mathrm{T}}$ when administering FCV did not increase the proportion of overdistended lung tissue. This fact underlines previous findings in non-individualized FCV showing a more even ventilation pattern [14-16]. The observed better lung aeration and more homogeneous gas distribution improve ventilation efficiency, not only by increasing gas exchange surface and diffusion capacity, but also by reducing intrapulmonary shunt fraction and improving the ratio between ventilation and perfusion. However, further studies are needed to investigate the exact shunt fraction and ventilation/perfusion ratio in FCV. 

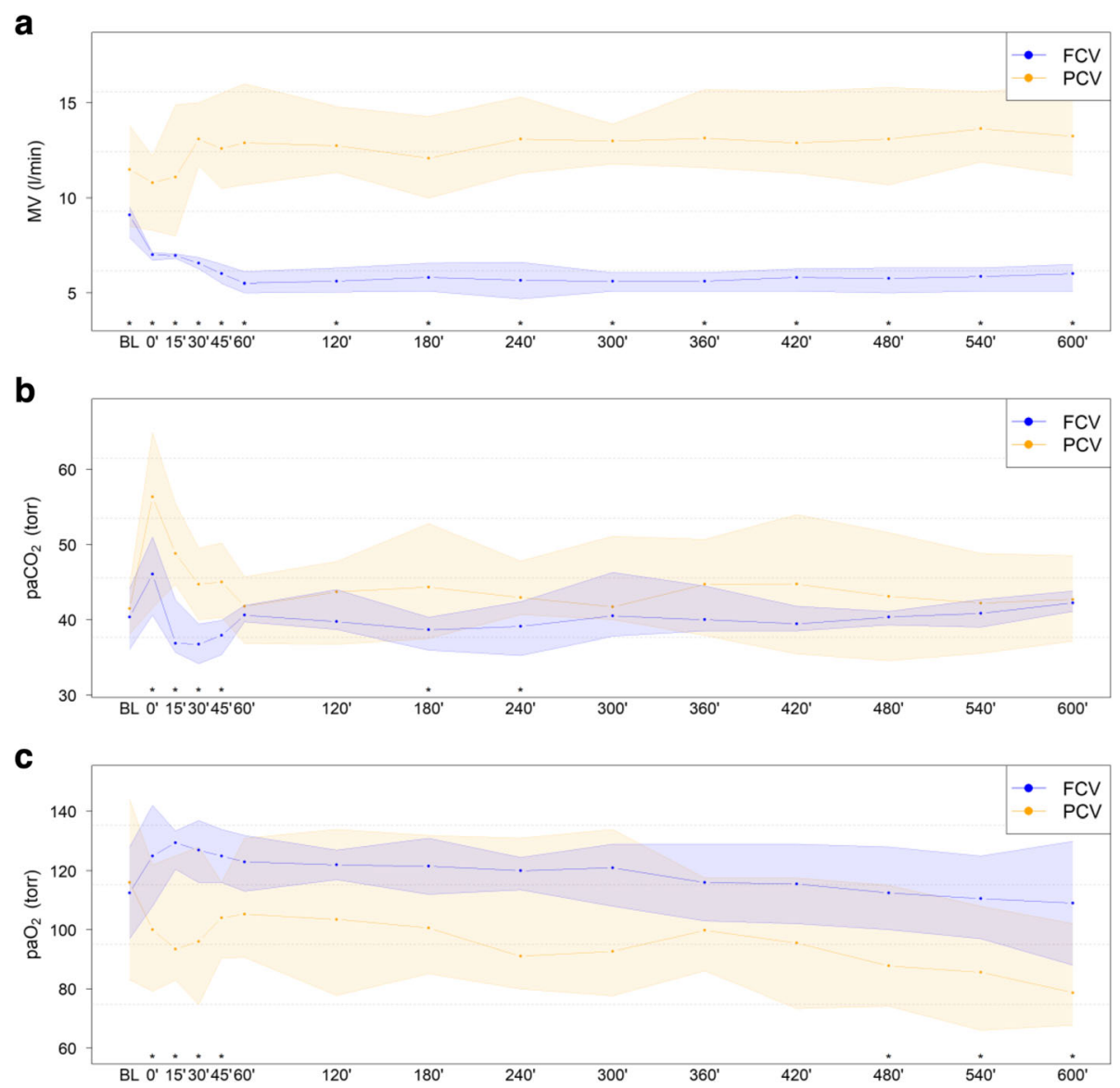

Fig. 2 Course of parameters over 10-h ventilation with FCV or PCV. a Respiratory minute volume (MV). $\mathbf{b}$ Arterial partial pressure of carbon dioxide. c Arterial partial pressure of oxygen at a fixed 0.3 fraction of inspired oxygen

The results of a trial in healthy piglets suggest that the energy delivered by the ventilator to the lung tissue contributes to VILI [7]. However, established calculations for mechanical power applied to the lung tissue consider only the inspiratory effort since expiration is presumed to be a passively occurring process. In earlier work on the concept of FCV, we already hypothesized that energy dissipated in the lung tissue during both inspiration and

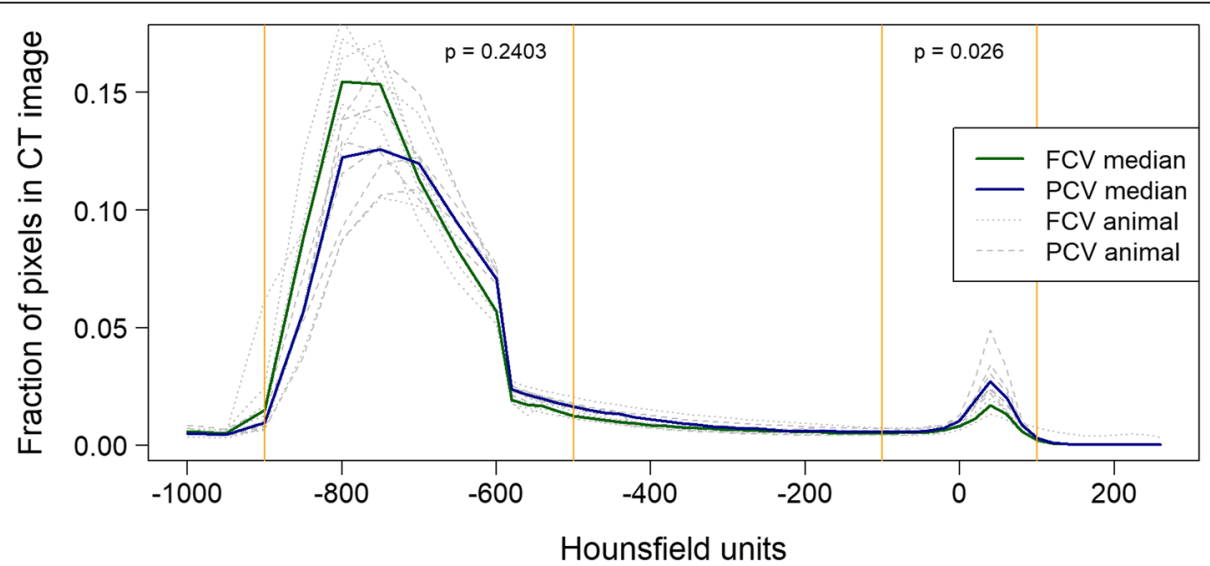

Fig. 3 The Hounsfield unit (HU) distribution after $10 \mathrm{~h}$ of ventilation. Defining lung tissue aeration as non-aerated (HU 100 to -100$)$, poorly aerated ( $\mathrm{HU}-101$ to -500$)$, normal aerated (HU -501 to -900$)$, and overdistended (HU -901 to -1000 ) revealed no increase in overdistended, but a significant decrease in non-aerated lung tissue $(p=0.026)$ 
expiration is an important contributor to VILI $[5,6]$. In mechanical ventilation, energy is necessarily dissipated because of resistive work that needs to be performed in order to overcome airway and tissue resistance during inspiration as well as expiration. Part of the applied energy is stored during inspiration (by expanding the (visco)elastic lung tissue and chest), can be partly recovered during expiration (by elastic recoil), and leaves the lung tissue again (during the egress of respiratory gas). By contrast, the dissipated energy (which represents the unavoidable "loss" of energy of any working mechanical system) remains in the lung tissue. In order to minimize dissipated energy, a constant flow of respiratory gas at the lowest level is most favorable [5]. Decelerating flow in PCV during inspiration and expiration results in two spikes where energy is dissipated. Contrarily, constant flow in FCV lacks any energy spikes delivered to and dissipated in the lung tissue [6]. Therefore, individualized FCV is performed not only with the greatest efficiency with respect to lung mechanics at the lowest flow guaranteeing normoventilation, but also with the lowest possible energy input to lung tissue.

Moreover, dynamic stress and strain, both undisputed contributors to VILI [17-20], are reduced in FCV due to steady, slow changes in pressure and smooth increase or decrease in lung volume during the whole ventilation cycle at an optimally low RR (see digital content: Additional file 1).

Our study has several limitations. First, the measured technical dead space of the Evone $^{\circ}$ ventilator is $25 \mathrm{ml}$ lower than that of the EvitaXL ${ }^{\bullet}(50 \mathrm{ml}$ vs. $75 \mathrm{ml})$, contributing to a higher MV in the PCV group. Moreover, the RR required to achieve normocapnia was significantly higher with PCV. However, correction of MV with consideration of technical and RR-related dead space ventilation effects still yields a significant MV reduction in FCV animals (5.0 vs $9.6 \mathrm{l} / \mathrm{min}$ ). Taking into account the significantly higher baseline MV of $2.4 \mathrm{l} / \mathrm{min}$ in the PCV group due to a slightly higher body weight (Table 1), a considerably reduced MV still results in the FCV animals (approx. 5.0 vs. $7.1 \mathrm{l} / \mathrm{min}$ ). This aligns our findings of improved ventilation efficiency with previous findings [12].

Second, PEEP in the FCV group was adjusted by means of measurement of dynamic lung mechanics. In the PCV group, however, PEEP was set at $5 \mathrm{~cm} \mathrm{H}_{2} \mathrm{O}$ according to the recommendations of the ARDS Network [17] for low tidal volume ventilation in healthy lungs. We acknowledge, this may not represent a truly "fair fight" between FCV and PCV; however, a PEEP level of $5 \mathrm{~cm} \mathrm{H}_{2} \mathrm{O}$ was used in a previous preclinical study investigating the effects of FCV versus VCV making our results very roughly comparable to this trial [12]. It may be argued that oxygenation could be improved by applying a slightly higher PEEP level in the PCV group; on the other hand, we observed improved oxygenation in the FCV group despite a significantly lower PEEP level. Finally, the aim of the current study was to compare ventilation based on evidence-based fixed numbers with settings based on an individualized approach.

Although more recent studies suggest using personalized ventilator settings based on electrical impedance tomography measurements and repeated CT scans [4], this approach was not feasible in our study due to a lack of resources and does not reflect clinical routine nor was it possible to perform PEEP titration guided by transpulmonary pressure due to anatomical issues related to the measurement of esophageal pressure $\left(P_{\mathrm{es}}\right)$ as a surrogate parameter for pleural pressure (Table 1). The location of the esophagus is far more dorsal in pigs than in humans and therefore $P_{\mathrm{es}}$ reflects only pleural pressure at the very dependent parts of the lungs and would have led to unacceptably high PEEP titration in order to keep transpulmonary pressure positive. Besides the fixed PEEP level in PCV, no recruitment maneuvers were performed either with PCV or FCV. Recruited lung tissue might have led to redistribution of the fixed tidal volume in $\mathrm{PCV}$ and thus a more homogeneous distribution of transpulmonary pressure through interdependence properties and, after an increase of lung compliance, a reduction of driving pressure. In the absence of recruitment maneuvers, it has to be stated that ventilator settings based on inspiratory pressure-volume curves may not provide enough information to guarantee safe mechanical settings.

Third, it is not possible to directly quantify atelectasis in the Hounsfield unit (HU) distribution, because atelectatic tissue lies in the same HU range as blood vessels and soft and fat tissue (- 100 to 100). Therefore, technically it is not possible to distinguish between atelectasis and non-alveolar lung tissue. However, since the amount of non-alveolar lung tissue inside the thoracic cavity should be roughly equal in healthy pigs, we hypothesize that the significant differences seen in the CT scan presentation are attributable to atelectasis. Additionally, CT images were taken during a hold maneuvers representing a static $\mathrm{CT}$ acquisition of a dynamic process; this fact is even more important for FCV than for PCV as in FCV normally any pause during ventilation is absent.

Finally, this study investigated lung healthy pigs with a comparable low compliance compared to humans. Thus, accepted VILI indicators such as tidal volume, driving pressure, and mechanical power are not fully transferable to humans, especially not under different pathophysiological conditions such as ARDS.

\section{Conclusion}

This porcine long-term ventilation study demonstrates the applicability of compliance-guided individualization 
of FCV settings. Additionally, compared to low tidal volume PCV, more efficient gas exchange with improved oxygenation, more efficient $\mathrm{CO}_{2}$ elimination, and more homogeneous gas distribution without signs of overinflation in FCV were confirmed. Our results for individualized FCV and the underlying concept for reducing dissipated energy (according to accepted thermodynamic considerations in the technical field) and minimizing stress and strain are suggestive of a more lungprotective ventilation strategy than is the current best clinical practice PCV. Further studies and clinical trials are consequently needed to determine and investigate long-term effects of individualized FCV under different pathophysiological conditions.

\section{Supplementary information}

Supplementary information accompanies this paper at https://doi.org/10. 1186/s13054-020-03325-3.

Additional file 1.

\section{Abbreviations}

ARDS: Acute respiratory distress syndrome; Cl: Cardiac index; Cl: Confidence interval; CO: Cardiac output; CT: Computed tomography; CVP: Central venous pressure; EELV: End-expiratory lung volume; ETT: Endotracheal tube; FCV: Flow-controlled ventilation; $\mathrm{FiO}_{2}$ : Fraction of inspired oxygen; HR: Heart rate; HU: Hounsfield unit; ICU: Intensive care unit; I:E ratio: Inspiration to expiration ratio; MAP: Mean arterial pressure; MD: Median difference; MPAP: Mean pulmonary arterial pressure; MV: Respiratory minute volume; OR: Odds ratio; $\mathrm{PaCO}_{2}$ : Arterial partial pressure of carbon dioxide; $\mathrm{paO}_{2}$ : Arterial partial pressure of oxygen; PCV: Pressure-controlled ventilation; PCWP: Pulmonary capillary wedge pressure; PEEP: Positive end-expiratory pressure; $P_{\text {es: }}$ : Esophageal pressure; $P_{\text {peak: }}$ Peak pressure; PVR(I): Pulmonary vascular resistance (index); RR: Respiratory rate; SVR(I): Systemic vascular resistance (index); VCV: Volume-controlled ventilation; VILI: Ventilator-induced lung injury; $V_{T}$ : Tidal volume; $\Delta P$ : Driving pressure

\section{Acknowledgements}

Not applicable.

\section{Authors' contributions}

$P S, J M, J A$, and GP planned and executed the study. BG performed the computed tomography and supervised image processing and Hounsfield unit analysis. TH did the statistical analysis and created tables and graphs for data presentation. TB and DE instructed PS, JM, JA, and GP how to individualize FCV and contributed to the discussion. Otherwise, TB and DE were not involved during study execution or data analysis. All authors read and approved the final manuscript.

\section{Funding}

No external source of funding was involved in this study.

\section{Availability of data and materials}

The datasets used and analyzed during the current study are available from the corresponding author on reasonable request.

\section{Ethics approval and consent to participate}

This study was approved by the Institutional Animal Care and Use Committee of the Medical University of Innsbruck and the Austrian Ministry of Science, Research and Economy (protocol no. BMBWF-66.011/0097-V/3b/ 2018). The study was conducted at the Experimental Research Unit of the Department of Anesthesiology and Intensive Care Medicine of the Medical University of Innsbruck and was performed in accordance with EU regulations for animal experiments (EU Directive 2010/63 of the European
Parliament and the European Council); reporting is in accordance with current ARRIVE guidelines.

\section{Consent for publication}

Not applicable.

\section{Competing interests}

TB has current patent applications on calculating and displaying dissipated energy and differentiating airway and tissue resistance and is a paid consultant to Ventinova Medical. DE represents the inventor of EVA and FCV technology (Ventrain, Tritube, Evone), has royalties for EVA and FCV technology (Ventrain, Tritube, Evone) and patent applications on calculating and displaying dissipated energy and differentiating airway and tissue resistance, and is a paid consultant to Ventinova Medical. All other authors have no competing interests to declare.

\section{Author details}

${ }^{1}$ Department of Anaesthesia and Intensive Care Medicine, Medical University of Innsbruck, Innsbruck, Austria. ${ }^{2}$ Department of Radiology, Medical University of Innsbruck, Innsbruck, Austria. ${ }^{3}$ Department of Mathematics, Faculty of Mathematics, Computer Science and Physics, University of Innsbruck, Innsbruck, Austria. ${ }^{4}$ University of Greenwich, London, UK. ${ }^{5}$ Faculty of Medicine, University of Münster, Münster, Germany.

Received: 16 July 2020 Accepted: 4 October 2020

Published online: 25 November 2020

\section{References}

1. Beitler JR, Malhotra A, Thompson BT. Ventilator-induced lung injury. Clin Chest Med. 2016;37(4):633-46.

2. Slutsky AS, Ranieri VM. Ventilator-induced lung injury. N Engl J Med. 2013; 369(22):2126-36.

3. O'Gara B, Talmor D. Perioperative lung protective ventilation. BMJ. 2018;362:k3030

4. Nieman GF, Satalin J, Gatto LA, et al. Personalizing mechanical ventilation according to physiologic parameters to stabilize alveoli and minimize ventilator induced lung injury (VILI). Intensive Care Med Exp. 2017:5(1):8.

5. Barnes T, van Asseldonk D, Enk D. Minimisation of dissipated energy in the airways during mechanical ventilation by using constant inspiratory and expiratory flows - flow-controlled ventilation (FCV). Med Hypotheses. 2018; 121:167-76.

6. Barnes T, Enk D. Ventilation for low dissipated energy achieved using flow control during both inspiration and expiration. Trends Anaesth Crit Care 2019;24:5-12.

7. Gattinoni L, Tonetti T, Quintel M, et al. Ventilator-related causes of lung injury: the mechanical power. Intensive Care Med. 2016:42(10):1567-75.

8. Putzer G, Braun P, Mair P, et al. Effects of head-up vs. supine CPR on cerebral oxygenation and cerebral metabolism - a prospective, randomized porcine study. Resuscitation. 2018;128:51-5.

9. Swindle MM, Makin A, Frazier KS, et al. Swine as models in biomedical research and toxicology testing. Vet Pathol. 2012;49(2):344-56.

10. Gattinoni L, Caironi P, Goodman LR, et al. What has computed tomography taught us about the acute respiratory distress syndrome? Am J Respir Crit Care Med. 2001;164(9):1701-11.

11. Chiumello D, Gotti M, Guanziroli M, et al. Bedside calculation of mechanical power during volume- and pressure-controlled mechanical ventilation. Crit Care. 2020;24(1):417.

12. Schmidt J, Wenzel C, Schumann S, et al. Improved lung recruitment and oxygenation during mandatory ventilation with a new expiratory ventilation assistance device: a controlled interventional trial in healthy pigs. Eur J Anaesthesiol. 2018;35(10):736-44.

13. Schmidt J, Wenzel C, Schumann S, et al. Flow-controlled ventilation attenuates lung injury in a porcine model of acute respiratory distress syndrome: a preclinical randomized controlled study. Crit Care Med. 2020; 48(3):e241-8.

14. Schmidt J, Günther F, Schumann S, et al. Glottic visibility for laryngeal surgery: Tritube vs. microlaryngeal tube: a randomised controlled trial. Eur J Anaesthesiol. 2019;36(12):963-71.

15. Weber J, Schmidt J, Schumann S, et al. Flow-controlled ventilation improves gas exchange in lung-healthy patients - a randomized interventional crossover study. Acta Anaesthesiol Scand. 2020;64(4):481-8. 
16. Weber J, Straka L, Schumann S, et al. Flow-controlled ventilation (FCV) improves regional ventilation in obese patients - a randomized controlled crossover trial. BMC Anesthesiol. 2020;20(1):24.

17. Acute Respiratory Distress Syndrome Network - Brower RG, et al. Ventilation with lower tidal volumes as compared with traditional tidal volumes for acute lung injury and the acute respiratory distress syndrome. N Engl J Med. 2000;342(18):1301-8.

18. Cressoni M, Cadringher P, Gattinoni L, et al. Lung inhomogeneity in patients with acute respiratory distress syndrome. Am J Respir Crit Care Med. 2014; 189(2):149-58.

19. Retamal J, Bergamini BC, Bruhn A, et al. Non-lobar atelectasis generates inflammation and structural alveolar injury in the surrounding healthy tissue during mechanical ventilation. Crit Care. 2014;18(5):505.

20. Chen ZL, Song $Y L$, Chen $Y Z$, et al. An estimation of mechanical stress on alveolar walls during repetitive alveolar reopening and closure. J Appl Physiol. 2015;119(3):190-201.

\section{Publisher's Note}

Springer Nature remains neutral with regard to jurisdictional claims in published maps and institutional affiliations.

Ready to submit your research? Choose BMC and benefit from:

- fast, convenient online submission

- thorough peer review by experienced researchers in your field

- rapid publication on acceptance

- support for research data, including large and complex data types

- gold Open Access which fosters wider collaboration and increased citations

- maximum visibility for your research: over $100 \mathrm{M}$ website views per year

At BMC, research is always in progress.

Learn more biomedcentral.com/submissions 